University of South Florida

DIGITAL COMMONS

Digital Commons @ University of

@ UNIVERSITY OF SOUTH FLORIDA

South Florida

FMHI Publications

Louis de la Parte Florida Mental Health Institute

(FMHI)

January 1991

\title{
Psychosocial correlates of fire disaster among children and adolescents
}

Russell T. Jones

David Paul Ribbe

Phillippe Belton Cunningham

Follow this and additional works at: https://digitalcommons.usf.edu/fmhi_pub

Part of the Mental and Social Health Commons

\section{Scholar Commons Citation}

Jones, Russell T.; Ribbe, David Paul; and Cunningham, Phillippe Belton, "Psychosocial correlates of fire disaster among children and adolescents" (1991). FMHI Publications. 2.

https://digitalcommons.usf.edu/fmhi_pub/2

This Article is brought to you for free and open access by the Louis de la Parte Florida Mental Health Institute (FMHI) at Digital Commons @ University of South Florida. It has been accepted for inclusion in FMHI Publications by an authorized administrator of Digital Commons @ University of South Florida. For more information, please contact digitalcommons@usf.edu. 
Psychosocial Correlates of Fire Disaster among Children and ADOLESCENTS

$$
\begin{aligned}
& \text { Russell T. Jones } \\
& \text { David P. Riser } \\
& \text { Philippe Cunningatam }
\end{aligned}
$$

University of Colorado, Institute of Behavioral Science, Natural Hazards Research and Applications Information Center

Quick Response Research Report \# 46

1991 



\title{
PSYCHOSOCIAL CORRELATES OF FIRE DISASTER \\ AMONG CHILDREN AND ADOLESCENTS
}

\author{
By \\ Russell T. Jones \\ David P. Ribbe \\ Phillippe Cunningham \\ Department of Psychology \\ Virginia Polytechnic Institute \\ and State University \\ Blacksburg, VA 24061-0436 \\ $703-231-5934$ \\ QUICK RESPONSE RESEARCH REPORT \#46
}

1991

This publication is part of the Natural Hazards

Research \& Applications Information Center's ongoing

Quick Response Research Report Series.

http://www.colorado.edu/hazards

The views expressed in this report are those of the authors and not necessarily those of the Natural Hazards Center or the University of Colorado. 



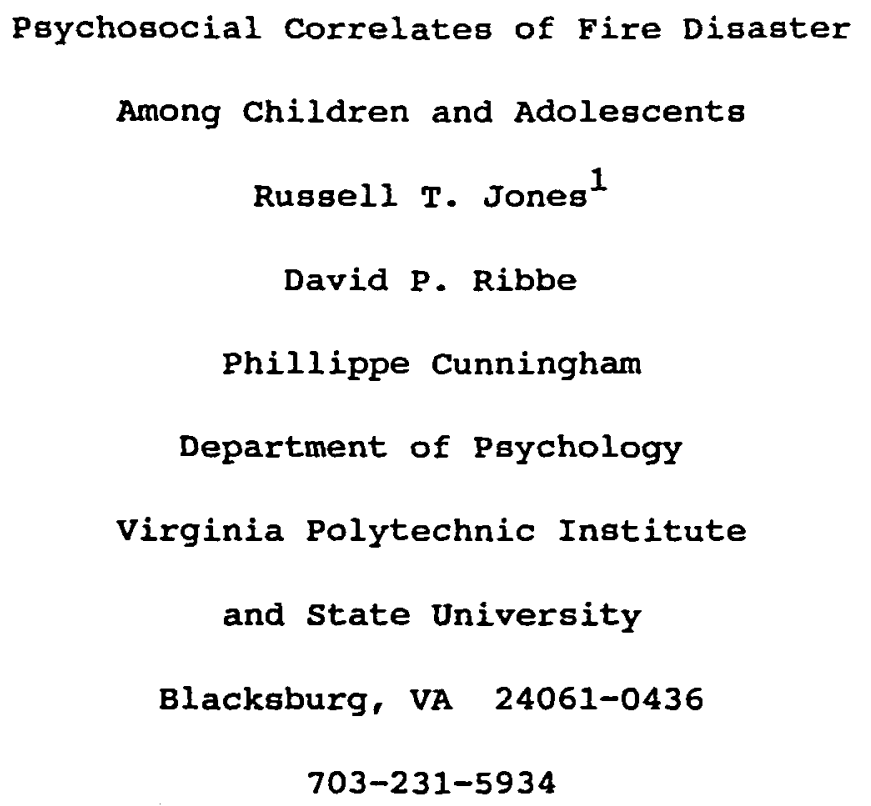

Running Head: Fire Disaster 


\begin{abstract}
This study examined the extent of children's and adolescents' psychosocial maladjustment associated with a natural disaster, namely, wildfire. The course of psychopathology was assessed two months after a major wildfire destroyed 420 homes. Not only were victims' individual responses evaluated, but also their functioning relative to their parents and to a comparison group from the same community, matched for age, gender, socioeconomic status, and fire insurance. The major goal of this study was to assess systematically the short-term mental health consequences of a wildfire disaster among children and adolescents. This goal was achieved through the use of standardized assessment procedures. The results of this study add useful information to the literature concerning the impact of disaster among children and adolescents and provide a methodological framework for future efforts in this area.
\end{abstract}

Key Words: Child, adolescent, disaster, post-traumatic stress disorder 
While the impact of disaster on children's psychological functioning has been addressed (see Davidson \& Baum, 1990, for a review), much ambiguity and speculation remain concerning the nature and degree of resulting trauma. Studies which have examined child victims of disaster targeting floods (Newman, 1976), and nuclear accidents (Three Mile Island; Handford, Mayes, Mattison, Humphrey, Bagnato, Bixler, \& Kales, 1986) report symptoms including nightmares, inability to sleep, anxiety, depression, acting out, guilt, and fear. Although some theorists have maintained that the disturbances following such events are often minimal and shortlived (Garmezy \& Rutter, 1985), others have stated that such consequences are relatively dramatic and longlasting (Yule \& Williams, 1990). The need for continued study in this area to define more precisely the consequences and identify mediators and moderators (i.e., the community, person variables nature of the event, degree of exposure to the event) of children's functioning following disaster is quite obvious.

Attention to several methodological shortcomings which have plagued both child- and adult-focused disaster studies may enhance the accuracy of conclusions drawn from future efforts. In the context of this pilot investigation designed to assess the consequences of wildfire on children and their parents, shortcomings found in many earlier studies will be addressed. Among those targeted are: 1) lack of standardized assessment measures and procedures, 2) inability to account for pre-existing levels of psychopathology in disaster victims, and 3) failure to utilize control groups. Each will be dealt with in turn. Although some innovations have led to a gradual emergence of standardized assessment batteries (Lyons, 1991), much continued progress 
is warranted. For example, the lack of standardized assessment batteries consisting of psychometrically sound instruments and standard clinical interviews administered by experienced clinicians continues to lead to invalid conclusions. Green (1982) and others view this shortcoming as a major problem plaguing the field. Unfortunately, these shortcomings are not unique to studies targeting children but also surface in the adult disaster literature (Solomon, 1989).

A related problem concerning assessment procedures is the reliance on adults to report children's reactions to disaster. Several researchers have limited their assessment of children's reactions to disaster to parent and/or teacher reports. In many instances, the degree of severity experienced by children often has been underestimated (Earls, Smith, Reich, \& Jung, 1988; McFarlane, 1987). Discrepancies in child and adult reports have been shown by Handford et al., (1986) where they conclude that children's and parents' perceptions of the severity of trauma differ. These findings attest to the necessity of assessing child victims themselves.

A common threat to findings resulting from traumatic events is researchers' lack of attempts to account for victims' pre-existing psychopathology. Data have shown that children with pre-existing psychiatric disorders are vulnerable to the development of other psychiatric symptoms (Earls et al., 1988). Our findings in a previous investigation support these conclusions (Jones \& Ribbe, 1991). While explanations for this phenomenon exist guch as the diathesis-stress view of psychopathology (Zubin \& Spring, 1977), assessment strategies which tap previous and/or present psychopathology are essential. 
The need for well-controlled and well-designed research in the scientific study of the consequences of disaster is obvious. The use of matched control groups provides one step toward achieving this objective. The benefit of control groups has been documented by numerous authorg when carrying out clinical research (Aptekar \& Boore, 1990). Indeed, a compelling case can be made for the inclusion of control groups in studies examining the consequences of disaster. While researchers have examined children's reactions to a variety of manmade and natural disasters (Handford et al., 1986; Newman, 1976; Saigh, 1985), other events require investigation. Relatively little research has been carried out regarding the impact of fire (Jones \& Haney, 1984; Jones \& Ribbe, 1991). Given that the devastating consequences of fires and burns ranked sixth among the major causes of injury and death among persons from birth to age 19 years (Division of Injury control, Center for the Environmental Health and Injury Control, Centers for Disease Control, 1990), research of this nature is warranted.

While the classic work by McFarlane and his colleagues provided data attesting to the consequences of bush fires in Australia, no gingle investigation exists which specifically targets children who experienced fire in the United States. One of the few studies designed to examine the mental health impact of fire emergencies on adults and children was carried out by $\operatorname{Krim}(1983)$. With regard to immediate impact, the mental health states of mother and child were significantly related to the extent of damage or loss incurred. A variety of behavioral symptoms including inability to eat or sleep, nervousness, anxiety, depression, and denial were reported. Additionally, parents were often emotionally 
unresponsive to their children after the fire. It is interesting to note that many of these reactions parallel those resulting from more large-scale disasters reported in the disaster literature (Training Manual for Human Service Workers in Major Disasters, 1983). Though these data are anecdotal in nature and require more systematic study, they do shed some light on mental health consequences of fire. Thus, the primary goal of this study was to identify children's reactions to fire disaster while addressing shortcomings of previous attempts in disaster research.

A specific research question to be explored was: to what extent do symptoms of post-traumatic stress disorder (PTSD) result from a firerelated disaster. Although the assessment of PTSD symptoms in children has been rare until recently, several investigations have suggested that children are susceptibile to developing PTSD symptoms following traumatic events. For example, PTSD symptoms have resulted from bush fires (McFarlane, Policansky, \& Irwin, 1987), fatal sniper attack (Pynoos, Nader, Frederick, Gonda, \& Stuber 1988), witnessing of parental murder (Malmquist, 1986), floods (Earls et al., 1988), and death of a sibling (Applebaum \& Burns, 1991). More recently, residential fire has been shown to produce similar symptoms in adolescent boys (Jones \& Ribbe, 1991).

To this end, children, adolescents, and parents ${ }^{2}$ were individually interviewed. Objective classification of responses using a multi-method strategy employing standardized diagnostic assessment instruments as well as widely used self-report measures were engaged. An attempt was made to account for major types of pre-existing and present psychopathology often related to PTSD, and to match fire victims with 
control subjects on variables including income level, insurance coverage, age, and gender. Description of the Disaster site

On June 27, 1990, a devastating wildfire spread through a small city in southern California. The fire struck at approximately $g i x$ o'clock in the evening. Many residents learned about the wildfire as they were preparing the evening meal and watching the evening news on television. Initial news reports suggested to viewers that the fire had originated at the city landfill, and that it was being controlled by firefighters. However, subsequent reports indicated that a second fire had developed high on the mountain range which abuts the city and residential areas. Viewers were confused about the location of the fire and the degree to which their homes were threatened. Many took no action until they could see the fire racing toward their homes, just a block or two away.

The second fire swept down the dry brush on the mountainside, fueled by wind gusting up to 60 miles an hour and temperatures exceeding $100^{\circ} \mathrm{F}$. In addition, the area had been experiencing a severe drought for the past five years, and conditions were very dry. The fire quickly reached the outgkirts of the city, where it proceeded to cut a swath through single-family dwellings through to a major highway, where it was finally halted on July 1. A major evacuation of several thousand residents caused considerable difficulty for the firefighting teams and firefighting equipment. Losses included one fatality, 420 single-family homes, 4 public buildings, 1 mobile home, 2 farm buildings, 10 business structures, and 26 apartment units. As of the last report, property damage estimates exceeded $\$ 250 \mathrm{million}$. 
Methods

Subjectg

All subjects resided in the affected city. They were interviewed between August 13 and 19, 1990. Victims, defined as individuals whose home had sustained significant damage or total destruction as a result of the wildfire, were identified and recruited primarily with the aid of the local chapter of the American Red Cross. Other sources included individual community members, local fire departments, churches, schools, newspaper reports, journalists, and national television newscasts. The Red Cross assisted in recruiting subjects by distributing brief screening questionnaires to families and/or individuals who came to the office to apply for various types of volunteer and government assistance for victims. Families who reported having children between the ages of 6 and 18 who were affected by the fire were contacted by telephone to schedule an interview.

A number of non-victimized (control) subjects were recruited with the aid of newspaper articles, schools, and individual referrals. The information from these individuals served as comparison data to assist in assessing the degree of impact of the wildfire on victims" psychosocial functioning. To enhance the homogeneity of the sample, we attempted to include control families and individuals with compatible demographic variables including age, gender, income level, and insurance coverage.

The demographic characteristics of the victim and control groups were quite similar. Most participants were of middle class status. There were 13 children in the victim group. They ranged in age from 7 to 11 years of age, with a mean age of 9.1 years. Four were male, and 
nine were female. There were ten white and three Mexican-American children.

There were nine children in the control group. They ranged in age from 7 to 12 years of age, with a mean age of 9.8 years. Four were male, and five were female. Two children were African-American, three were Mexican-American, and four were white.

There were ten adolescents in the victim group. They ranged in age from 13 to 18 years of age, with a mean age of 14.5 years. Three were male, and seven were female. Seven were white, two were AfricanAmerican, and one was Mexican-American. There was only one 13 year-old, African-Mexican-American adolescent male in the control group. Procedures

The method of interviewing involved a systematic assessment of the psychosocial consequences of experiencing the fire. In the context of a cross-sectional design, a multi-method strategy was employed to examine the psychosocial adjustment of children and adolescents using selected portions of a structured diagnostic interview (DICA-R; Reich \& Welner, 1990), the Horowitz Impact of Events Scale (HIES; Horowitz, Wilner, \& Alvarez, 1979), the state-Trait Anxiety Inventory for Children (STAI-C; Speilberger, Gorsuch, Lushene, Vagg, \& Jacobs, 1977), the Children's Behavioral Questionnaire for Completion by Parents (CBQ; Rutter, 1967), and the Fire Questionnaire-Child Form (FQ-C; Jones \& Ribbe, 1990 ).

DICA-R. The DICA-R is a revised version of the Diagnostic Interview for Children and Adolescents, which is a semi-structured poychiatric interview modeled after the adult Diagnostic Interview Schedule (DIS; Robins, Helzer, Croughan, Williams, \& Spitzer, 1981 ). The DICA-R was designed to identify psychiatric symptoms and make 
psychiatric diagnoses in children and adolescents as specified by the DSK-III-R (American Psychiatric Association, 1987). The majority of the questions can be answered yes or no, with yes indicating a positive symptom.

DICA-R symptoms asgessed were those of past major affective disorder (Past MAD), present major affective disorder (Present MAD), conduct disorder (CD), oppositional defiant disorder (ODD), overanxious disorder (OAD), and post-traumatic stress disorder (PTSD). These disorders were selected inasmuch as symptoms of depression and anxiety are commonly associated with PTSD (American Psychiatric Association, 1987). In addition, impulsive behaviors common among conduct disordered individuals have been observed in children following traumatic events (Davidson \& Baum, 1990; Saigh, 1985). It was considered important to ascertain the extent to which any of these symptoms were present prior to the fire, in order to isolate the impact of the fire.

HIES. The HIES is a 15-item, self-report questionnaire designed to provide a cross-sectional picture of subjective psychological responses to stressful life events. Factor analysis identified two factors: 1) intrusive thoughts and affects; and 2) avoidance behaviors. Within this study, the wildfire served as the referent for both victims and control subjects. Responses are indicated on a four-point scale ranging from "not at all" (scored 0), "rarely" (scored 1), "sometimes" (scored 3), and "often" (scored 5). For the purposes of this study, a simplified version of the HIES was developed for use with children between the ages of 6 and 12 .

\section{Children'B Behaviour Questionnaire for completion by parents}

(CBQ). The CBQ is a 31-item parent self-report scale. It is primarily 
used to discriminate between types of behavioral and emotional disorders as well as differentiate children who show or do not show disorder. Two subscales are derived, namely, neurotic and antisocial. The test-retest reliability is .74 and inter-rater reliability is .64 (Rutter, 1967). Fire questionnaire-child Form. The child version of the Fire Questionnaire (FQ-C; Jones \& Ribbe, 1990) consists of three sections: (1) demographics, (2) stressful life events, which includes checklists and descriptions of natural disasters and traumatic events, and (3) orientation, which is composed of 13 questions pertaining to firerelated events, thoughts, feelings, losses, and other consequences of the fire. The test-retest reliability of the $F Q$ is .87 .

\section{Interviews}

Individual interviews were carried out at either the Red Cross headquarters or one of two local churches near the affected area. Each interview lasted approximately 60 minutes, with a range of 45 to 90 minutes. Approximately half of the time was spent completing the selfreport instruments; the other half, interviewing. Breaks were provided as needed.

Prior to the interview, all participants were read a consent form describing the purpose and parameters of the study. Families were reimbursed $\$ 25.00$ for their participation. Following each interview, information concerning local mental health agencies were provided. Those individuals who appeared to be having severe adjustment problems were encouraged to seek professional help through these agencies. Interviewer Training

Data were collected by a team of four trained interviewers. Two interviewers were third- and fourth-year graduate students in the 
clinical psychology program at Virginia Polytechnic Institute \& state University. Both had Master's degrees at the time of the interviews and had been trained twice a week for a total of at least 51 hours. Training sessions consisted of becoming familiar with each measure, videotaping and critiquing role-plays and interviews, observations of the interview given at least once, detailed instructions about administration, testing over presented material, and reliability checks. Both graduate interviewers had previous experience collecting similar data from 15 to 20 victims of another fire. The third interviewer was an advanced undergraduate psychology major who underwent extensive training as well. He was trained in multiple sessions according to an interview training protocol developed by the graduate interviewers, and underwent numerous inter-rater reliability checks with the other interviewers. In addition to other training, each student interviewer learned the DSM-III-R diagnostic criteria for each disorder of interest in this study. At the end of training, inter-rater reliability averaged .91.

The fourth interviewer was the principal investigator who has a Ph.D. and is a licensed Clinical Psychologist. He supervised the interviewers' training and the actual implementation of the study. Results

The analyses of data from the california wildfire focused on: (1) between-group comparisons of demographic characteristics; (2) a betweengroup comparison of PTSD diagnosis and symptom patterns as measured by DICA-R; (3) between-group comparisons of short-term stress-related psychopathology and overall levels of PTSD and stress-related symptomatology (HIES and STAI-C); (4) degree of PTSD symptom agreement 
in parent-child dyads (DIS and DICA-R); (5) the relationship of preexisting psychopathology to short-term stress levels (DICA-R and $\mathrm{CBQ})$; and (6) the relationship of previous stressors to short-term stress levels (HIES, DICA-R, and STAI-C). Demographics

Statistical analyses confirmed that the victim and control groups did not differ on any of the following demographic characteristics: income level, fire insurance, age, and gender. DICA-R PTSD Diagnosis

Three subjects met the diagnostic criteria for PTSD. One was an 8-year old girl, another was a 7-year old male, and the third was a 15year old girl from a group home for troubled adolescents who also met the diagnostic criteria for preexisting oppositional defiant disorder. The two girls were in the victim group; the boy in the control group. All three were Mexican-American.

An examination of the DICA-R symptom patterns reported by the three PTSD cases revealed positive symptoms on the first (recurrent and intrusive distressing recollections of the event), second (recurrent distressing dreams of the event), fifth (efforts to avoid thoughts or feelings associated with the trauma), sixth (efforts to avoid activities or situations that arouse recollections of the trauma), eighth (markedly diminished interest in significant activities), twelfth (difficulty falling or staying asleep), and sixteenth (exaggerated startle response) DICA-R items. 


\section{DICA-R Symptoms}

Victims and controls were compared on the number of symptoms reported on each of the five psychiatric diagnostic categories, including $O D D, C D, O A D$, past and pregent $M A D$, and PTSD.

Due to the lack of adolescent control subjects $(\mathrm{N}=1)$ and the fact that no age differences were found on number of DICA-R symptoms, child and adolescent data were combined and analyzed on each dependent variable. A series of univariate analyses of variance (ANOVAs) were performed, one on the number of symptoms and criteria of each of the $D I C A-R$ disorders assessed. The effect for group was found to be nonsignificant $(p>.05)^{3}$ for the number of symptoms reported on ODD, $C D$, OAD, past MAD, or present MAD. No difference in the number of symptoms endorsed by the two groups was found for PTSD, $E(1,31)=0.04$, $\mathrm{p}=.84$. The victims endorsed an average of 4.4 PTSD symptoms, compared to 4.1 symptoms endorsed by controls (Table I). Table II shows the percentage of victims versus controls reporting individual PTSD symptoms.

Insert Tables I and II about here

There was, however, a significant difference in the number of PTSD criteria met, $\mathrm{F}(1,31)=5.44, \mathrm{p}=.03$. Victims met an average of 2.8 out of 5 PTSD criteria compared to an average of 1.6 criteria met by the controls. Of the 23 victims, two met the criteria for diagnosable PTSD, while one of the 10 controls was diagnosed as suffering from PTSD.

The gignificant difference between groups on PTSD may have been due to preexisting group differences on the first, inclusionary criterion (experienced traumatic event). Thus, two-by-two frequency 
tables were constituted to reflect the number of subjects qualifying or not qualifying under each criterion according to group membership. Fisher's Exact Test (left-tail) showed that only the first criterion (experienced traumatic event as defined by losing a home to fire) significantly discriminated between groups, $\mathrm{p}=.001$. The number of subjects meeting the remaining criteria did not differ significantly between groups: for the second criterion (intrusion), $\mathrm{p}=.25$, the third criterion (avoidance), $\mathrm{p}=.85$, the fourth criterion (increased arousal), $\mathrm{p}=.60$, and the fifth criterion (duration), $\mathrm{p}=.09$. A twoway factorial multivariate analysis of variance (MANOVA) with group and gender as the independent variables and the number of psychiatricrelated criteria (intrusion, avoidance, and arousal) as the dependent variables.revealed no significant effects for group, gender, or interaction.

HIES Symptoms

Due to reasons stated earlier, child and adolescent data were combined. A two-way factorial MANOVA was performed on the summated intrusion and avoidance subscale scores with group and gender as the independent variables. There was a significant main effect for group, $\underline{F}(2,28)=3.39, \underline{P}=.048$, but neither the main effect for gender, nor the interaction was significant.

Intrusion subscale. Two-way factorial ANOVAs were performed using the model described above. On the intrusion subscale, effects for group and gender were not sifnificant nor was there a sifnificant interaction. The victim group scored an average of 15.1 on the intrusion subscale compared to 11.6 scored by the control group. 


\begin{abstract}
Avoidance subscale. On the avoidance subscale, there was a significant main effect for group, $\underline{F}(1,29)=5.96, \underline{p}=.02$. Effects for gender and the interaction were not gignificant. The victim group scored an average of 20.2 on the avoidance subscale compared to 10.4 scored by the control group. The means and standard deviations for the 1-month post-disaster subscores for children are summarized in Table III, and the means and standard deviations for the 1-month post-disaster subscores for children and adolescents are summarized in Table IV.
\end{abstract}

Insert Tables III and IV about here

Total score. Horowitz (1982) suggested cutoff scores for determining low, medium, and high symptom levels using the total scores $(<8.5=$ low; $8.6-19.0=$ medium; and $>19.0=$ high $)$. Therefore, a two-way factorial ANOVA was performed on the combined child and adolescent data with group and gender as the independent variables and the total scale score as the dependent variable. While the effect for gender and the interaction were non-significant, the effect for group approximated significance, $\underline{F}(1,29)=4.02, \underline{p}=.054$. Subjects in both the victim group and the control group scored in the "high" range as defined by Horowitz (1982), with the victims averaging 35.3 total points, and the controls averaging 22.0 .

Table $V$ reflects the percentage of children who had experienced symptoms at least once in the seven days prior to the date of asgessment. Table VI reflects the percentage of adolescent victims alone who had experienced these symptoms. 
A two-way factorial ANOVA was performed on the combined child and adolescent data with group and gender as the independent variables and the total number of endorsed items as the dependent variable. There was a significant effect for group, $\underline{F}(1,29)=4.27, \underline{p}=.048$, but the effect for gender and the interaction were non-significant. $\underline{\text { STAI-C }} \underline{\text { Data }}$

A two-way factorial MANOVA was performed with group and gender as the independent variables and the state and trait subscale scores as the dependent variables. Child and adolescent data were combined for these analyses. The effect for group was not significant, but the effect for gender was significant, $\underline{F}(2,26)=5.64, \underline{p}=.009$. The interaction was non-significant.

Two factorial ANOVAs were performed using the model described above. Group, gender and interaction effects were not significant on the state or trait portions of the STAI-C. The data from the STAI-C indicated that anxiety levels were near normal for both victims (mean state anxiety score $=33.7$; mean trait anxiety score $=36.5$ ), and controls (mean state anxiety score $=30.6 ;$ mean trait anxiety score $=$ 36.6) (See Table VII).

Insert Table VII about here

Parent-Child PTSD Comparisons

Parents, children, and adolescents were compared in terms of the number of PTSD symptoms reported on the DIS and the DICA-R. An independent $t$-test showed that, as a group, parents reported significantly more PTSD symptoms than did children, $t=2.07, \mathrm{p}=.04$. When parent-child dyads were compared in terms of the total number of 
PTSD symptoms reported, a dependent $t$-test based on difference scores revealed that, on average, parents reported 1.9 more symptoms than their children, which was significant, $\underline{t}=2.63, \mathrm{p}=.048$.

To examine further the degree of association between aymptom agreement in parent-child dyads, the numbers of PTSD symptoms reported by parents and their children were correlated. There was a significant, but not very strong, association between the number of PTSD symptoms reported by parents and children, $\underline{\underline{I}}=.39, \mathrm{p}=.05$.

In addition, another, more specific means of assessing the degree of agreement on individual PTSD symptoms between parent-child dyads was employed. Because the DICA-R and DIS yield "yes" or "no" (dichotomous) data, the phi-coefficient was used to determine the strength of association between parents' responses to individual PTSD symptoms and those of their children. This statistic was employed to examine the degree to which specific PTSD symptom contagion existed between parents and their children in this disaster sample.

For each parent-child dyad $(\mathrm{N}=26)$, a phi coefficient was determined by constituting $2 \times 2$ matrices of yes-no responses for all PTSD symptoms. The mean phi-coefficient was only .048 , indicating no agreement within parents and children dyads on either the presence or absence of specific PTSD symptoms. When this mean was tested against the hypothesis that it was equal to 0 , the wilcoxon signed-rank test showed that the degree of agreement between parent-child dyads on PTSD symptoms was not significant, $\underline{z}=0.75, \underline{p}=.23$. Pre-existing Psychiatric Disorders

DICA-R data. Again, there were no significant differences between groups in terms of the number of pre-existing psychiatric symptoms. The 
DICA-R data revealed that four children and four adolescents could be diagnosed with preexisting psychopathology. of the children, three met the diagnostic criteria for overanxious disorder. The fourth child met the criteria for previous PTSD resulting from a severe injury. of the two adolescents who met the diagnostic criteria for oppositional defiant disorder, one met the criteria for conduct disorder, as well. An additional adolescent met the criteria for conduct disorder alone, and the fourth adolescent met the criteria for overanxious disorder. of the three children with diagnosable PTSD, one had no preexisting psychiatric disorders, one had preexisting PTSD from a severe injury, and the third could be diagnosed with preexisting oppositional defiant disorder. CBQ data. According to parents' ratings on the CBQ, six subjects in the sample scored 13 or more, a cut-off point which usually indicates a high risk of psychiatric disorder. Four of the subjects above the cut-off were children; two were adolescents, both of which were from a group-home for troubled girls. Their CBQs were completed by the grouphome parent who accompanied them to the interview. Three subjects were from the fire victim group (including the adolescents), and three were control subjects. The mean total score on the CBQ was 7.36 for the child and adolescent victims, and 8.22 for the child and adolescent controls.

Previous Stressors

Children and adolescents were asked if they had ever experienced stressful life events such as another disaster or severe trauma other than the wildfire. Events included: earthquake, other fire, flood, mudslide, severe storm, toxic waste, severe injury, car accident, "getting beat up", witness injury to other, severe illness, or "other." 
of the 22 children ages 7 to 12,9 said they had never experienced another stressful event, eleven reported one stressful event, and two reported two stressful events. Four of the children who reported previous stressful events had experienced an earthquake, four had experienced or witnessed a car accident, two reported a severe injury, and one each reported a storm and fire, broken arm, Hurricane Hugo, and "getting beat up". One of the children who had experienced a severe injury (a broken arm from falling out of a tree onto concrete) also reported multiple PTSD symptoms following the injury, including geveral reexperiencing, avoidance, and arousal symptoms.

of the 11 adolescents, 5 said that they had never experienced another stressful event, and 6 reported one stressful event. Two had experienced an earthquake; two witnessed an injury; and one each reported "getting beat up" and having a car accident.

Comparisons were made between those children and adolescents who did not report previous stressors and those who reported one or two previous stressors. One-way analyses of variance (ANOVAs) were performed with previous stressor as the independent variable, and stress-related scores or symptoms as the dependent variables. On the HIES, there was no main effect of previous stressor status for either the intrusion or avoidance subscale scores or the total score. With the DICA PTSD data, there was no main effect for the number of intrusion, avoidance, arousal, or total PTSD symptoms. Similarly, with the STAI-C, there was no main effect for either state or trait anxiety score.

$$
\text { Discussion }
$$

Consistent with an earlier study, varying degrees of psychosocial distress result from a fire disaster (McFarlane, 1987). While the 
sample size of children and adolescents was quite small, results parallel those found in other disaster-related research (Earls et al., 1988; Handford et al., 1986; Yule \& Williams, 1990). Several attempts were made to enhance the methodological sophistication of this study through the employment of multimethod assessment strategy and the use of a control group. Additionally, the use of a structured interview (DICAR) assisted in isolating the impact of the fire by accounting for several types of pre-existing psychopathology in the form of PTSD, ODD, $C D$, OAD, past and present $M A D$, and previous trauma experienced.

Although three individuals met the criteria for PTSD (two children and one adolescent), extreme caution must be taken when interpreting these findings. Two of the children were quite young, ages 7 and 8 . As pointed out by Green et al. (in press) and others, young children may have difficulty in expressing their reactions to disaster. This may be due to several factors, including inability to perceive an event as harmful and/or physically threatening, inability to process the event as a function of cognitive deficiencies, inability to understand interview questions, inability to verbalize their feelings, and/or cultural differences. After examining transcripts of the interviews, several of these hypotheses may be plausible. The fact that both children and adolescents were Mexican-American enhances the likelihood of difficulty in expressing reactions due to language and/or cultural differences. The need to consider cultural issues when assessing the impact of disaster on culturally different groups is, hence, important in future research. The mediating factors contributing to the development of psychopathology in disaster situations may have an intringic cultural meaning (Bravo, Rubio-Stipec, \& Canino, 1990). Another reason to 
interpret these data cautiously is due to the presence of previous psychiatric disorders. The eight-year-old child had experienced a traumatic event (a fall resulting in a broken arm) which appeared to have been of sufficient intensity to lead to PTSD. The adolescent had been previously diagnosed with oppositional defiant disorder. We are uncertain of the degree to which previous stressors may have contributed to these individuals' present level of PTSD symptomatology. These findings shed light on the issue raised by Solomon and Canino (1990) concerning the extent to which psychiatric sequelae resulting from exposure to an extraordinary traumatic event, such as a fire disaster in this instance, differ from the sequelae resulting from exposure to more common stressors (injury). Obviously, this issue should be pursued further.

Although it is fairly clear that a major proportion of the victims did not experience diagnosable PTSD, the consistent level of PTSD symptoms (victims 4.4 total symptoms, controls 4.1 total symptoms) suggests that the fire did negatively impact their behavior. The nonsignificant differences across the six types of disorder and previous trauma suggest that PTSD symptomatology was primarily due to the fire. of course, further well-designed research is needed to explore this hypothesis.

When interpreting the data, it is important to consider the relatively comparable levels of PTSD symptoms on the DICA-R endorsed by both the victim and control groups, a finding obtained by Jones and Ribbe (1991). While these results may seem counterintuitive, upon closer examination they may be quite reasonable. Given that most residents were highly aware of the wildfire because of its magnitude and 
extent of immediate media coverage, it is likely that all individuals were affected by this event. While we contend that victims may have experienced a greater level of trauma, which is particularly supported by our adult data, we also maintain that all residents of this community were negatively affected to some degree by the fire.

Several researchers have provided heuristic frameworks in which these findings might be interpreted. One framework concerns degree of exposure to the event which has correlated with individuals' reactions to trauma. The impact of exposure can be garnered from investigations of several events, including Three Mile Island (Bromet, 1980), the sniper attack at school (Pynoos et al., 1988) alluded to earlier, and fire (Maida, Gordon, Steinberg, \& Gordon, 1989) where greater exposure to the traumatic event led to greater levels of PTSD symptoms.

The HIES revealed a significant difference on the avoidance subscale between the victimized and control groups. The relatively high elevations on this subscale for victims suggest that the fire did produce emotional reactions. Upon closer inspection of subjects' responses, a greater percent of victims endorsed all eight items than did control subjects. It is interesting to note that the greatest discrepancy between groups was on the item, "I stayed away from things that reminded me of it." One rather parsimonious explanation for this difference was that victims and/or their parents may have actively avoided the site of their destroyed home. At a theoretical level, these findings are consistent with earlier reports which maintain that children may avoid reminders of the traumatic event because their reactions may intensify under such circumstances (Davidson \& Baum, 1990). We conclude as do Davidson and Baum (1990) that it is important 
to view the outcome of stressful events as a function of an interaction among characteristics of the person, the environment, as well as the event.

Concerning the intrusion subscale, substantial but nonsignificant differences were observed between victims and controls on six of the seven symptoms. Nevertheless, the victims again evidenced greater levels of PTSD symptomatology. Particular symptoms which suggest a greater level of distress among the victims include, "I thought about it when I didn't mean to," "I had strong feelings about it," "I had dreams about it," and "other things kept making me think about it." Perhaps the most telling symptom, "I kept seeing it over and over in my mind," evinced the greatest discrepancy between groups. These patterns are consistent with other investigations documenting the impact of trauma on children and adolescents (Green et al., in press). The analyois of the total HIEs score yielded similar results.

The between-group difference on the avoidance subscale of the HIES does not square with the failure to find a difference between groups on the number of avoidance symptoms reported on the DICA-R. This finding highlights the need for further attention to assessment issues in this area. A plausible explanation of this apparent incongruity is that the HIES and DICA measure different aspects of the construct of avoidance. The avoidance construct assessed with the HIES is based on the pre-DSMIII notions of trauma-related avoidance or "numbing-of-responsivenessto-the-external world" symptoms (Brett, Spitzer, \& Williams, 1988). The avoidance symptoms assessed with the DICA are based on the DSM-III-R PTSD classification. 
Brett et al. (1988) pointed out that Horowitz et al. (1979) focused the HIES mainly on a two-dimensional concept of avoidance that refers to conscious attempts to dispel thoughts and feelings associated with the trauma. By contrast, the DSM-III-R expanded the DSM-III "numbing" category to include avoidance, amnesia, and numbing symptoms. An examination of the respective items of the HIES and the DICA-C-R in Table VIII revealed that six of the eight HIES "avoidance" items did indeed appear to load on one of the two DSM-III-R symptoms related to efforts to deal with thoughts and feelings associated with the disaster, but none of the HIES avoidance items lined up with any of the five remaining DSM-III-R avoidance symptoms.

\section{Insert Table VIII about here}

While the meaning of these discrepant findings is not totally clear, it does, however, underscore the necessity of examining closely the differences and similarities of instruments hypothesized to assess symptoms around the dimensions of the stress response. Heuristically, Horowitz et al. (1987) have shown that the avoidance concept as measured by the HIES does differentiate stressed from normal individuals, and between stressed individuals who seek treatment and those stressed individuals who do not seek treatment. It may be that victims scoring higher on HIES avoidance would be more responsive to clinical intervention; thus, the HIES avoidance scores, although limited in the scope of their assessment of PTSD-related avoidance symptoms, have significant clinical utility. 
Another difference between the finding as assessed by the HIEs and DICA-R is in the magnitude of the symptoms reported. Children in both the victim and control groups scored in the "high" range on the total HIES score, as defined by Horowitz. No such cutoff categories have been reported for the number of PTSD symptoms endorsed, but it seems that both groups reported a mild number of PTSD symptoms on the DICA-R (the mean numbers of symptoms reported by the victims and controls were 4.4 and 4.1, respectively). It is clear that there is a difference in stress-related symptoms as assessed by the two instruments. Lyons (1991) has recommended that in the assessment of PTSD the primary emphasis be placed on the results of a clinical interview, and that reliance on any single measure such as a score on a psychometric index should be avoided. In addition, Weisenberg, Solomon, \& Schwarzwaldt (1987) found only a 758 agreement between diagnoses based on psychometric indices and those based on clinical interviews. It is clear that the HIES assesses the intensity of some aspects of PTSD symptomatology, whereas the DICA-R primarily assesses the presence or absence of PTSD symptoms, representing two modes of assessing PTSD. It may be that a solution to this assessment difficulty is to develop an integrated assessment protocol that assesses both symptom presence and intensity.

Concerning the mediating role of parents' behavior on children's and adolescents ' functioning, Rutter, Cox, Tupling, Berger, and Yule (1975) hypothesized that three factors ameliorated the consequence of stress in children: personality, family cohesion, and support outside the family environment. While the scope of this study did not allow us 
to assess objectively these factors, we were able to gain some insight on the mediating role of parents.

Several recent studies have found that parental behavior during disaster may have a negative impact on their offspring's behavior. Indeed, McFarlane (1987) reported that mothers' reactions to disaster were better predictors of children having PTSD than children's direct exposure to the disaster itself. Melamed and siegel (1988) reported that parental anxiety was correlated with poor adjustment of children. Similarly, Pynoos, et al. (1988) stated that children are likely to respond similarly to adults in both the nature and frequency of grief reactions up to one year following the incident. This phenomenon was also observed by other investigators (Parkes, 1970; Rosenbeck \& Natan, 1985). In the present study, these findings were tentatively supported in that a low correlation was found between the number of symptoms of child/adolescent and parents across both target groups. However, there was some evidence to suggest that contagion of specific PTSD symptoms was non-existent within the parent-child dyads in this sample.

In an attempt to enhance the validity of children and adolescent reactions, we allowed children to report objectively their experiences during and after the event. Previous investigations in this area relying heavily on parent and/or teacher reports (Benedek, 1985; Eth, Silveratein, \& Pynoos, 1985) have been shown to underestimate children's level of stress significantly. In examining the youngster's responses, it is evident that varying levels of symptomatology were obtained.

Conversely, parents' perceptions of child and adolescent reactions using the CBQ suggested a somewhat different conclusion. Parents 
reported extremely low levels of endorgement of items on both the antisocial and neurotic subscales for subjects in both fire and control groups, which suggests that parents may have been unaware of their children's level of symptomatology •

When examining these results in light of children's elevated levels of distress, as indicated by the avoidance dimension of the HIES and the DICA PTSD scale, the discrepancies between children's reports and parents' reports of children are clear. These findings may be supportive of other investigations which claim that parents do in fact under-report severity of children's reactions to these types of events (Handford et al., 1985; MCFarlane, 1987; Earls et al.. 1988).

obviously, we are limited in our conclusions here, inasmuch as no confirming reports were obtained from other meaningful sources such as school teacher (due to summer vacation); the need for future empirical research is quite apparent.

When examining these findings, it is interesting to see how they compare with related studies assessing children's and adolescents' reaction to disaster. From Tables $I X$ and $X$ it is clear that reactions may be closely related to the severity of the consequences of the event. For example, reactions were significantly lower among boys who experienced a nighttime dorm fire where the major consequences were loss of personal belongings versus more intense reactions by individuals following the Herald of Free Enterprise sinking where several casualties resulted. This finding highlights the need to not only examine the type of event (i.e., fire, shooting, earthquake) but also the potential moderating or mediating effect of the severity of the consequences of the event. 
An obvious question arises when summarizing the results of this study as well as several others where relatively mild levels of PTSD result from similar disasters: Why is there such a low level of PTSD symptomatology reported by children and adolescents? several explanations have been proffered. One explanation stems from the fact that no residents were injured or killed. In those disasters where injury and/or death occur, or the fear of either is significant, the likelihood of PTSD becomes increasingly probable. Future investigations should include or use only those families where injury and/or death or the fear of either is reported.

Another explanation concerns children's developmental level as it interacts with their ability to perceive an event as harmful and/or physically threatening or as relatively harmless and non-threatening. It has been posited that young children may lack the capacity to be traumatized by certain events (Gomes-Schwartz, Horowitz, Sauzier, 1985 ). Convergely, as children continue to develop, they develop the cognitive weaponry to cope effectively with a traumatic event. This finding is consistent with several gained from the stress and coping literature. Compas, Malcarne, \& Fondacaro (1988) and others maintain that older children (12 to 14) as compared to younger children have greater problem-solving abilities and capacity to generate alternative ways of coping, both of which are correlated with positive outcomes.

The apparent cohesiveness of this community may have served an important protective role. Inasmuch as the role of community has been 
hypothesized to impact individuals' recovery rate (Erikson, 1976), the need to examine this factor in future investigations is essential. Notwithstanding the above-mentioned hypotheses, perhaps the most parsimonious explanations for the relatively mild levels of PTSD symptomatology are consistent with Garmezy's (1983) conclusion that accompanying disturbances following the psychological sequelae of manmade and natural disasters are often minimal and shortlived. Selecting only those subjects reporting difficulty in coping following disaster may be a more precise and fruitful method of examining the psychosocial consequences of fire. 


\section{References}

American Pgychiatric Asgociation (1987). Diagnostic and statistical Manual of Mental Disorders (Third Edition-Revised). Washington, DC: Author.

Applebaum, D. R., \& Bruns, G. L. (1991). Unexpected childhood death: Posttraumatic stress disorder in surviving siblings and parents. Journal of Clinical Child Psychology, 20, 114-120.

Bravo, M., Rubio-stipec,M., Canino, G. (1990). Methodological aspects of disaster mental health research. International Journal of Mental Health, 19, 37-50.

Brett, E. A., Spitzer, R. L., \& Williams, J. B. W. (1988). DSM-III-R criteria for posttraumatic stress disorder. American Journal of Psychology, 145, 1232-1236.

Carroll, E. M., Foy, D. W., Cannon, B. J., \& Zwier, G. (1991). Assegsment issues involving the families of trauma victims. Journal of Traumatic Stress, 4 , 25-40.

Compas, B. E., Malcarne, V. L., \& Fondacaro, K. M. (1988). Coping with stregs events in older children and young adolescents. Journal of Consulting and clinical Psychology, 55, 405-411.

Davidson, L. M., \& Baum, A. (1990). Posttraumatic stress in children following natural and human-made trauma. In $M$. Lewis \& $S$. M. Miller (Eds.), Handbook of developmental psychopathology (pp. 251259). New York: Plenum.

Division of Injury Control, Center for Environmental Health and Injury Control, Center for Disease Control (1990). Childhood injuries in the United States. American Journal of Diseases of Children, 144 , 627-646.

Earls, F., Smith, E., Reich, W., \& Jung, K. G. (1988). Investigating psychopathological consequences of a disaster in children: A pilot study incorporating a structured diagnostic interview. Journal of the American Academy of Child and Adolescent Psychiatry, 27, 90-95.

Erikson, K. T. (1976). Loss of community at Buffalo Creek. American Journal of Psychiatry, 133, 302 .

Garmezy, H., \& Rutter, M. (1985). Acute reactions to stress. In M. Rutter \& L. Hersov (Eds.), Child and adolescent psychiatry: Modern approaches (2nd Ed.) (Pp. 152-176). Publisher:

Green, B. L. (1982). Agsessing levels of psychological impairment following disaster. Journal of Nervous and Mental Disease, 170 , 544-552. 
Green, B. L., Korol, M., Grace, M. C., Vary, M. G., Leonard, A. C., Blaser, G. C., \& Smitson-Cohen, S. (in press). Children and disaster: Age and gender effects on PTSD symptoms. Journal of the American Academy of Child and Adolescent Psychiatry.

Handford, H. A., Mayes, S. D., Mattison, R. H., Humphrey, F. J., Bagnato, S., Bixler, E. O., \& Kales, J. D. (1986). Child and parent reaction to the Three Mile Island nuclear accident. Journal of the American Academy of Child Psychiatry, 25, 346-356.

Herjanic, B., \& Reich, W. (1982). Development of a structured psychiatric interview for children: Agreement between child and parent on individual symptoms. Journal of Abnormal Child Psychology, 10, 307-324.

Horowitz, M., Wilner, N., \& Alvarez, W. (1979). Impact of event scale: A measure of subjective stress. Psychomatic Medicine, 41, 209218.

Jones, R. T., \& Haney, J. I. (1984). Behavior therapy and fire emergencies: Conceptualization, assessment, and intervention. Progress in Behavior Modification, 19, 177-216.

Jones, R. T., \& Ribbe, D. P. (1991). Child, adolescent, and adult victims of residential fire. Behavior Modification, 139, 560-580.

Jones, R. T., \& Ribbe, D. P. (1990). The Adult and Child Fire Questionnaire. Unpublished manuscript, Virginia Polytechnic Institute and State University, Blacksburg, VA.

Klein, H. (1974). Child victims of the holocaust. Journal of Clinical Child Psychology, $\underline{3}, 44-47$.

Krim, A. (1983). Families after urban fire: Disaster intervention (MH29197). Washington, DC: National Institute of Mental Health.

Lyons, J. A. (1991). Issues to consider in assessing the effects of trauma: Introduction. Journal of Traumatic Stress, 4, 3-6.

Maida, C. A., Gordon, N. S., Steinberg, A., \& Gordon, G. (1989). Psychosocial impact of disasters: Victims of the Baldwin Hills fire. Journal of Traumatic stress, $\underline{2}, 37-47$.

Malmquist, C. P. (1986). Children who witness parental murder: Posttraumatic aspects. Journal of the American Academy of Child Psychiatry, 25, 320-325.

McFarlane, A. C. (1987). Family functioning and overprotection following a natural disaster: The longitudinal effects of posttraumatic morbidity. Australian and New Zealand Journal of Psychiatry, 21, 210-216. 
McFarlane, A. C., Policansky, S. K., \& Irwin, C. (1987). A longitudinal study of the psychological morbidity in children due to a natural disaster. Psychological Medicine, 17, 727-730.

Melamed, B. G., \& Siege?, L. J. (1988). Coping behaviors in children facing medical stress. In T. Field, P. McCabe, \& N. Schneiderman (Eds.), Stress and coping across development, Vol. 2 (pp. 109138). New York: Lawrence Erlbaum.

Newman, C. J. (1976). Children of disaster: Clinical observations at Buffalo Creek. American Journal of Psychiatry, 133, 306-312.

Pynoos, R. S., Nader, K., Frederick, C., Gonda, L., \& Stuber, M. (1988). Grief reactions in school-age children following a sniper attack at school. In E. Chigier (Ed.), Grief and bereavement in contemporary society, Vol. 1: Psychodynamics (pp. 29-41). London: Freund Publishing House.

Reich, W., \& Welner, Z. (1990). Diagnostic Interview for Children and Adolescents-Revised. St. Louis: Washington University.

Robins, I. M., Helzer, J. E., Croughan, J., \& Ratcliff, K. S. (1981). National Institute of Mental Health Diagnostic Interview Schedule. Archives of General Psychiatry, 38, 381-389.

Rosenbeck, R., \& Nathan, P. (1985). Secondary traumatization in children of Vietnam veterans. Hospital and Community Psychiatry, 36, 538-539.

Rutter, M., Cox, A., Tipling, C., Berger, M., \& Yule, W. (1975). Attainment and adjustment in two geographical areas. British Journal of Psychiatry, 126, 493-509.

Saigh, P. A. (1985). On the nature and etiology of traumatic stress. Behavior Therapy, 16, 423-426.

Solomon, S. D. (1989). Research issues in assessing disaster's effects. In R. M. Gist \& B. Lubin, Psychosocial aspects of disaster (pp. 308-340). New York: John Wiley.

Solomon, S. D., \& Canino, G. J. (1990). Appropriateness of DSM-III-R criteria for posttraumatic stress disorder. Comprehensive Psychiatry, 31, 227-237.

Weisenberg, M., Solomon, Z., \& Schwarzwaldt, J. (1987). Assessing the severity of PTSD: Relation between dichotomous and continuous measures. Journal of Clinical and Consulting Psychology, 55, 432434.

Yule, W., \& Williams, R. M. (1990). Post-traumatic stress reactions in children. Journal of Traumatic Stress, 3 , 279-295. 
Footnote

$1_{\text {This research was funded by two grants awarded to the first author from }}$ the National Hazards Center at the University of Colorado in Boulder and Virginia Tech University. Portions of this manuscript were presented at the 99th Annual American Psychological Association convention, August, 1991, in San Francisco, CA. Special thanks to Judy Lee at the National American Red Cross office in Washington, DC, and the following staff members at the Santa Barbara Red Cross chapter: Louise Peterson and Abby Keith. Also, special thanks to members of our research team, especially John Benesek and Anthony Constantino, and to Bob Frary for his statistical assistance. Thanks are also extended to Wendy Riech and Sam Turner for comments on an earlier version of the manuscript. All correspondence should be sent to Russell T. Jones, Virginia Tech Department of Psychology, Stress and Coping Lab, 4102 Derring Hall, Blacksburg, VA 24061-0436.

${ }^{2}$ Adult data, with the exception of parent-child dyad data, are not included in this report.

${ }^{3}$ significance level for all findings was $<.05$. 
Table I

Number of Symptoms Reported on the DICA-R by Children and Adolescents

\begin{tabular}{lcccccc}
\hline Disorder & Group & $\underline{N}$ & $\bar{X}$ & $\underline{\text { SD }}$ & F-value & p-value \\
\hline Oppositional Defiant & 1 & 22 & 1.18 & 1.59 & 1.21 & .28 \\
$\begin{array}{l}\text { Disorder } \\
\text { Conduct Disorder }\end{array}$ & 1 & 10 & 0.60 & 0.70 & & \\
& 2 & 22 & 0.68 & 1.21 & 0.44 & .51 \\
$\begin{array}{l}\text { Overanxious Disorder } \\
\text { (past) }\end{array}$ & 1 & 23 & 1.26 & 1.25 & 0.35 & .56 \\
$\begin{array}{l}\text { Major Affective Disorder } \\
\text { (past) }\end{array}$ & 1 & 23 & 2.57 & 2.19 & 0.32 & .57 \\
Major Affective Disorder & 1 & 10 & 3.10 & 3.07 & & \\
(present) & 2 & 10 & 0.90 & 1.10 & & .11 \\
Post-Traumatic Stress & 1 & 23 & 4.43 & 3.80 & 0.04 & .84 \\
Disorder & 2 & 10 & 4.10 & 5.07 & & \\
\hline
\end{tabular}

$a_{\text {Group }} 1$ = victim

Group 2 = Control 
Table II

Percentages of Children and Adolescents Reporting PTSD Symptoms on the DICA-R Following Disaster: Victims vs. Controls

\begin{tabular}{lccc} 
PTSD Symptoms & $\begin{array}{c}\text { Victims }(\%) \\
(\mathrm{n}=23)\end{array}$ & $\begin{array}{r}\text { Control } \\
(\mathrm{n}=10)\end{array}$ \\
\hline Reexperiencing & $\ddots \cdots \ddots$ & & \\
1. Thinking about it a lot & 65.0 & 40.0 \\
2. Dreaming about it repeatedly & 30.4 & 30.0 \\
3. Sense of event recurring & 21.7 & 30.0 \\
4. Upset by reminders of fire & 45.5 & 20.0
\end{tabular}

Avoidance

5. Thinking about it when trying not to $39.1 \quad 30.0$

6. Avoided things associated with fire $26.1 \quad 30.0$

7. Amnesia for details of fire $13.0 \quad 10.0$

8. Loss of interest in usual activities $\quad 17.4 \quad 20.0$

-9. Loss of interest in people $13.6 \quad 10.0$

10. Loss of caring feelings $4.4 \quad 0$

11. Outlook on future changed $\quad 4.4 \quad 10.0$

Increased Arousal

12. Trouble falling/staying asleep $47.8 \quad 40.0$

13. Increased irritability \& temper outbursts $26.1 \quad 20.0$

14. Decreased attention $13.6 \quad 50.0$

15. Increased restlessness $\quad 13.0 \quad 40.0$

16. Increased startle reflex $34.8 \quad 30.0$

17. Increased autonomic activity $34.8 \quad 0$ 
Table III

Means and Standard Deviations of 1-Month Post-Disaster HIES Subscales: Children Ages 7,-12

\begin{tabular}{lcrrr} 
Subscale & Group & $\underline{N}$ & $\bar{X}$ & $\underline{S D}$ \\
\hline Intrusion & 1 & 13 & 17.1 & 6.1 \\
& 2 & 9 & 12.0 & 9.2 \\
Avoidance & 1 & 13 & 22.8 & 7.5 \\
& 2 & 9 & 11.4 & 11.2 \\
Total & 1 & 13 & 39.8 & 12.5 \\
& 2 & 9 & 23.4 & 19.7 \\
\hline
\end{tabular}

$a_{\text {Group } 1}=$ victim

Group 2 = Control 
Table IV

Means and Standard Deviations of 1-Month

Post-Disaster HIES Subscales: Children and Adolescents

\begin{tabular}{lccrr} 
Subscale & Group & $\underline{N}$ & $\overline{\mathrm{X}}$ & $\underline{\text { SD }}$ \\
\hline Intrusion & 1 & 23 & 15.1 & 6.6 \\
& 2 & 10 & 11.6 & 8.7 \\
Avoidance & 1 & 23 & 20.2 & 9.2 \\
& 2 & 10 & 10.4 & 11.1 \\
Total & 1 & 23 & 35.3 & 14.3 \\
& 2 & 10 & 22.0 & 19.1 \\
a Group 1 = Victim & & & & \\
Group 2 = Control & & & &
\end{tabular}


Table $\mathrm{V}$

Reported Frequency (\%) of Horowitz Impact of Events: Scale: Children Ages 7-12

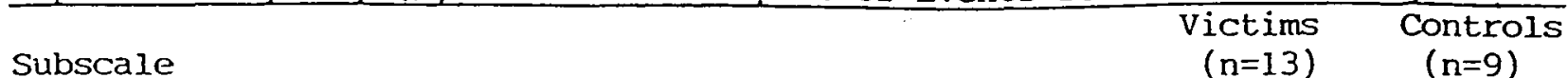

Intrusion

I thought about it when I didn't mean to

$100.0 \% \quad 88.9 \%$

I had trouble falling asleep or staying asleep because pictures or thoughts about it came into my mind

$53.9 \% \quad 55.6 \%$

I had strong feeling about it

$92.3 \% \quad 66.7 \%$

I had dreams about it

$61.6 \% \quad 44.4 \%$

I kept seeing it over and over in my mind

$92.3 \% \quad 41.4 \%$

Other things kept making me think about it

$69.2 \% \quad 66.7 \%$

Any reminjer brought back feelings about it

$69.2 \% \quad 55.6 \%$

\section{$\underline{\text { Avoidance }}$}

I stopped letting myself get upset when I thought about it or was reminded of it $84.6 \% \quad 44.4 \%$

I tried not to remember

$84.6 \% \quad 55.6 \%$

I stayed away from things that reminded me of it $69.2 \% \quad 22.2 \%$

I felt that it did not happen or that it was make-believe

$84.6 \%$ $44.4 \%$

I tried not to talk about it

$84.6 \%$

$44.4 \%$

I knew that I still had a lot of feelings about it, but I didn't deal with them $69.2 \% \quad 55.6 \%$

I tried not to think about it $84.6 \% \quad 55.6 \%$

I don't have feelings about it anymore $84.6 \% \quad 66.7 \%$ 
Table VI

Reported Frequency (\%) of Horowitz Impact of Events Scale: Adolescent Victims

Subscale

(\%) Victims

$(n=10)$

Intrusion

I thought about it when I didn't mean to

70

I had trouble falling asleep or staying asleep because

of pictures or thoughts about it that came into my mind

I had waves of strong feelings about it

80

I had dreams about it

Pictures about it popped into my mind

90

Other things kept making me think about it

90

Any reminder brought back feelings about it

90

\section{$\underline{\text { Avoidance }}$}

I avoided letting myself get upset when I thought about it or was reminded of it

I tried to remove it from memory

I stayed aray from reminders of it

I felt as if it hadn't happened or it wasn't real

I tried not to talk about it

I was aware that I still had a lot of feelings about it, but I didn't deal with them

I tried not to think about it 
Table VII

Means and Standard Deviations on the State-Trait Anxiety Inventory:

Children and Adolescents 1-Month Post-Disaster

\begin{tabular}{|c|c|c|c|c|c|}
\hline \multirow[b]{2}{*}{$\begin{array}{l}\text { STAI-C } \\
\text { Scale }\end{array}$} & & \multicolumn{2}{|c|}{ Painted Cave Fire } & \multirow{2}{*}{$\begin{array}{c}\text { Elementary } \\
\text { Males } \\
(n=456) \\
\end{array}$} & \multirow{2}{*}{$\begin{array}{c}\text { School Children } \\
\text { Females } \\
(n=457) \\
\end{array}$} \\
\hline & & $\begin{array}{c}\text { Victims } \\
(\mathrm{n}=21)\end{array}$ & $\begin{array}{c}\text { Controls } \\
(n=10)\end{array}$ & & \\
\hline state & $\begin{array}{l}\bar{X} \\
S D\end{array}$ & $\begin{array}{r}33.7 \\
8.1\end{array}$ & $\begin{array}{r}30.6 \\
3.2\end{array}$ & $\begin{array}{r}31.0 \\
5.7\end{array}$ & $\begin{array}{r}30.7 \\
6.0\end{array}$ \\
\hline Trait & $\begin{array}{l}\bar{X} \\
\underline{S D}\end{array}$ & $\begin{array}{r}36.5 \\
7.7\end{array}$ & $\begin{array}{r}36.6 \\
7.5\end{array}$ & $\begin{array}{r}36.7 \\
6.3\end{array}$ & $\begin{array}{r}38.0 \\
6.7\end{array}$ \\
\hline
\end{tabular}




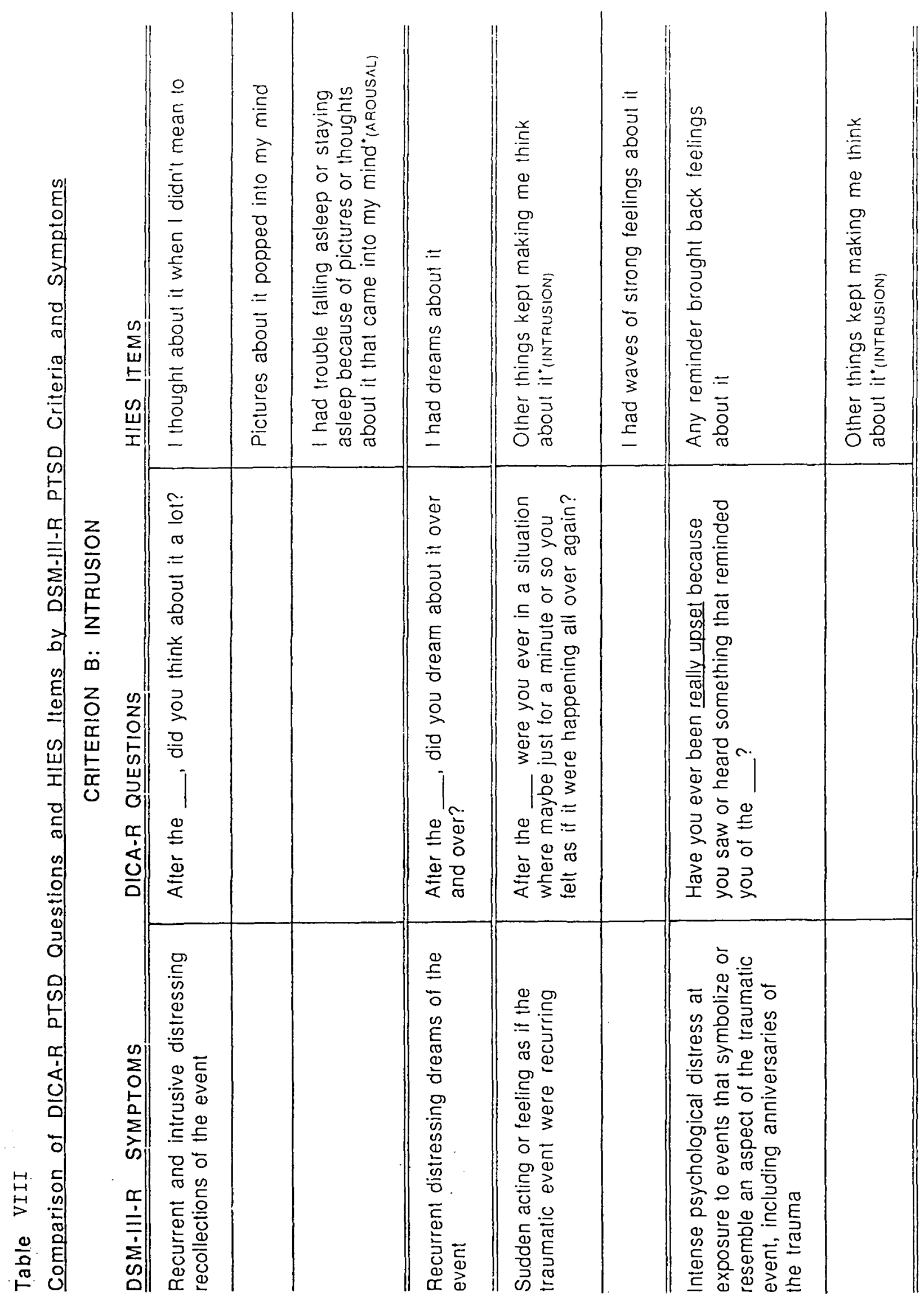




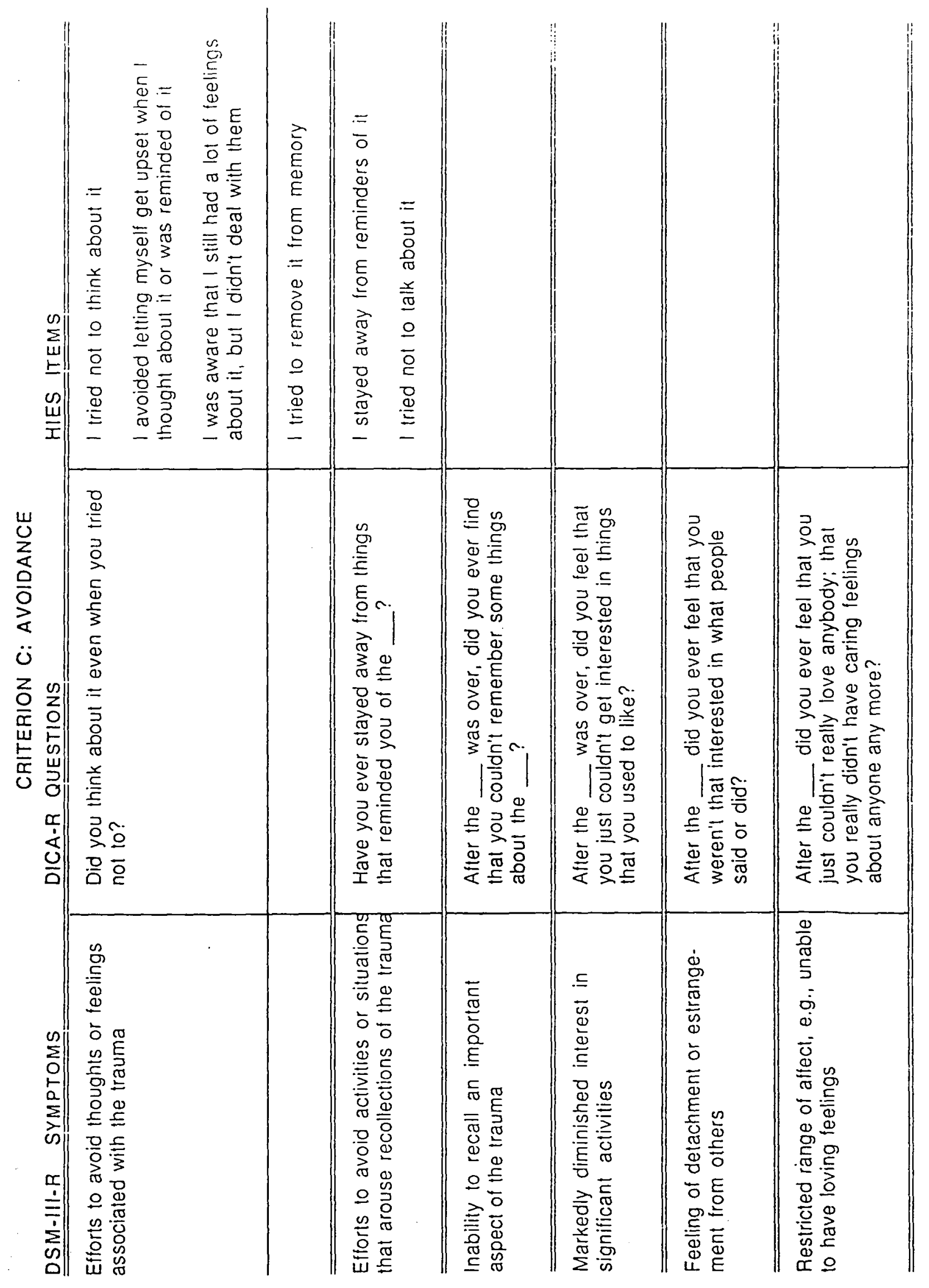



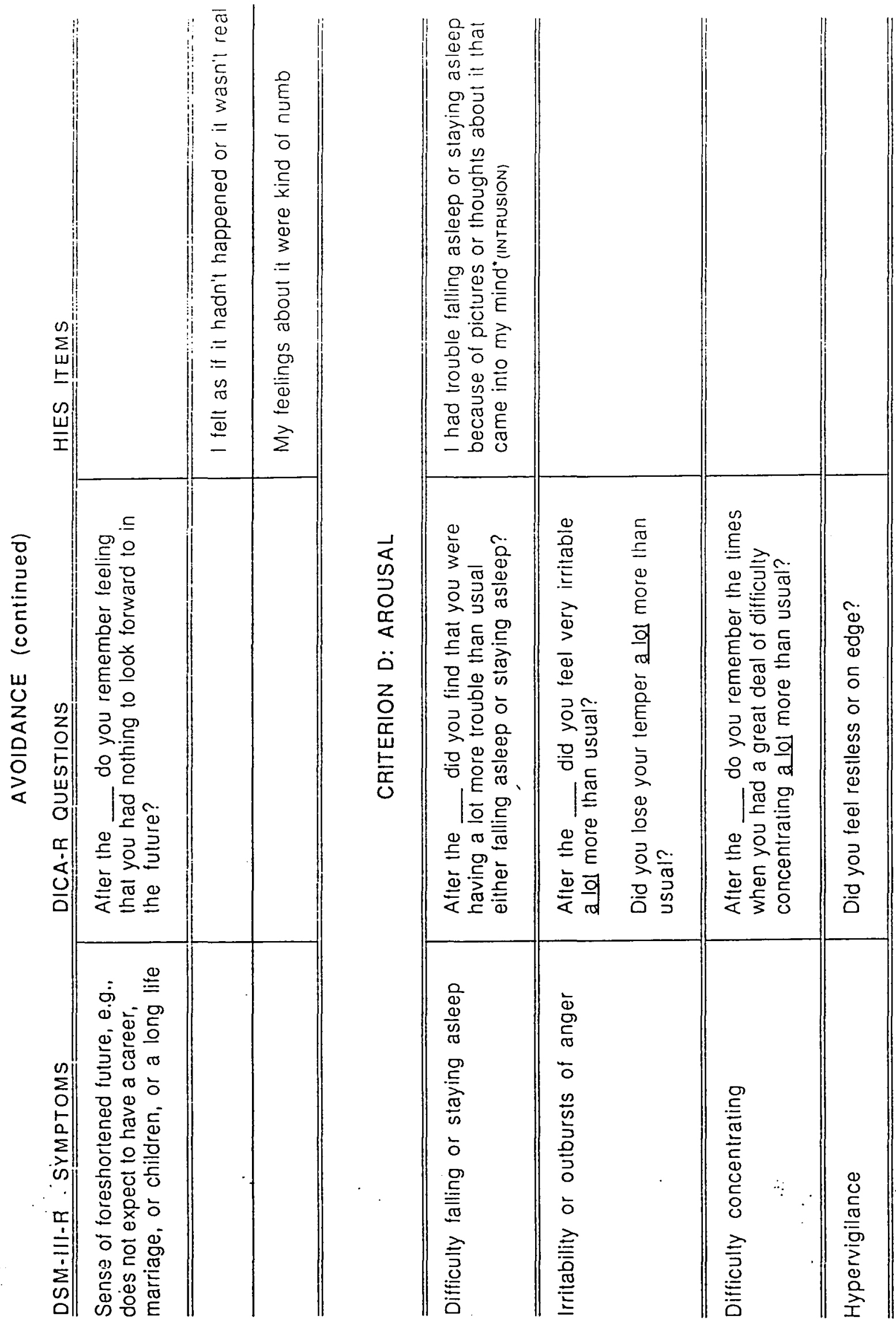


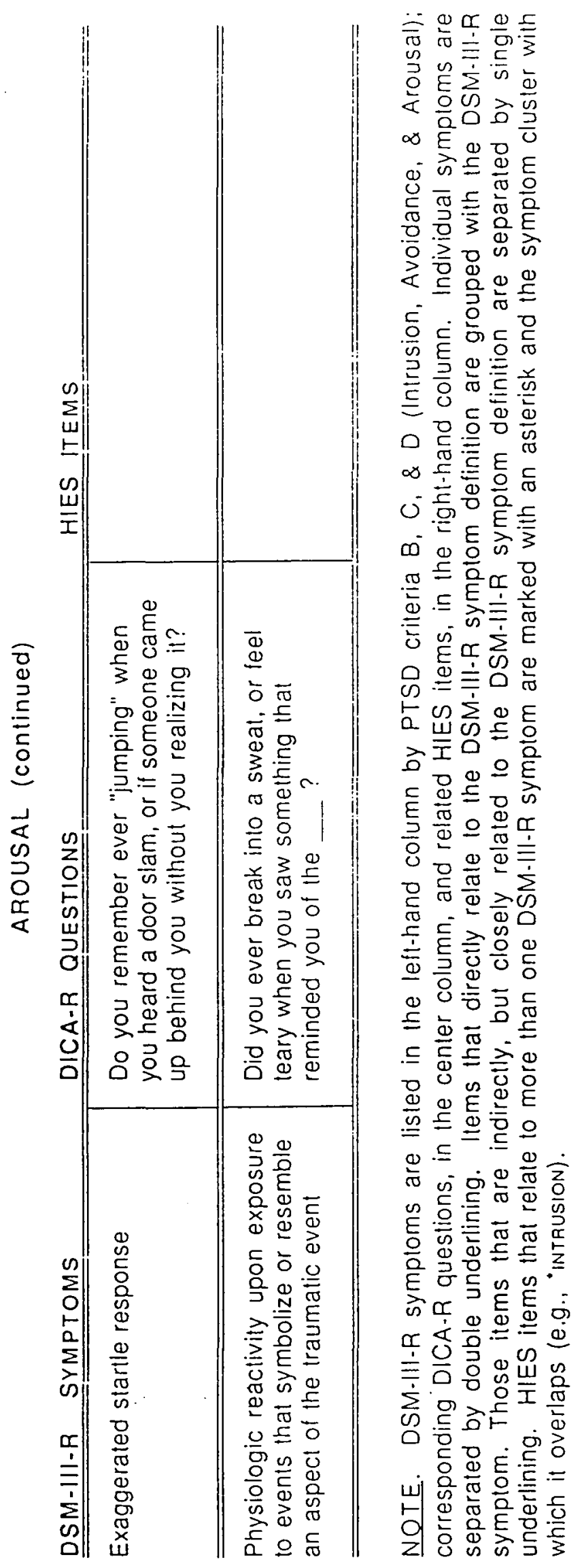


Table IX

Percentage of Subjects Endorsing HIES Intrusion and Avoidance Items and Mean HIES Subscale and Total Scores Across Four Studies

\begin{tabular}{|r|c|c|c|c|c|c|}
\hline \multicolumn{2}{|c|}{ Jones \& Ribbe (1990) } & Malmquist & \multicolumn{2}{c|}{ Jones \& Ribbe (1991) } & Yule \& Williams \\
\hline \multicolumn{2}{|c|}{ Ages 14-19 } & Ages 5-10 & \multicolumn{2}{c|}{ Ages 7-12 } & Ages 5-15 \\
\hline \multicolumn{2}{|c|}{ Victims } & Controls & Victims & Victims & Controls & Victims \\
\hline \multicolumn{2}{|c|}{$(\mathrm{n}=25)$} & $(\mathrm{n}=13)$ & $(\mathrm{n}=6)$ & $(\mathrm{n}=13)$ & $(\mathrm{n}=9)$ & $(\mathrm{n}=13)$ \\
\hline INT & $\%$ & $\%$ & $\%$ & $\%$ & $\%$ & \\
\hline 1 & 80.0 & 53.8 & 88.0 & 100 & 88.9 & \\
\hline 4 & 32.0 & 30.8 & 88.0 & 53.9 & 55.6 & \\
\hline 5 & 64.0 & 69.2 & 100 & 92.3 & 66.7 & \\
\hline 6 & 40.0 & 38.5 & 81.0 & 61.6 & 44.4 & \\
\hline 10 & 80.0 & 84.6 & 88.0 & 92.3 & 44.4 & \\
\hline 11 & 84.0 & 76.9 & 100 & 69.2 & 66.7 & \\
\hline 14 & 72.0 & 85.6 & 56.0 & 69.2 & 55.6 & \\
\hline AVD & & & & & & \\
\hline 2 & 76.0 & 61.5 & 50.0 & 84.6 & 44.4 & \\
\hline 3 & 68.0 & 61.5 & 50.0 & 84.6 & 55.6 & \\
\hline 7 & 52.0 & 38.5 & 69.0 & 69.2 & 22.2 & \\
\hline 8 & 48.0 & 30.8 & 63.0 & 84.6 & 44.4 & \\
\hline 9 & 48.0 & 57.1 & 98.0 & 84.6 & 44.4 & \\
\hline 12 & 56.0 & 38.5 & 63.0 & 69.2 & 55.6 & \\
\hline 13 & 64.0 & 53.8 & 75.0 & 84.6 & 55.6 & \\
\hline 15 & 52.0 & 61.5 & 50.0 & 84.6 & 66.7 & \\
\hline \hline & $\bar{x}$ & $\bar{x}$ & & $\bar{x}$ & $\bar{x}$ & \\
\hline INT & 13.4 & 11.3 & & 17.1 & 12.0 & 19.3 \\
\hline AVD & 14.6 & 10.9 & & 22.8 & 11.4 & 27.6 \\
\hline TOT & 28.0 & 22.2 & & 39.8 & 23.4 & 46.9 \\
\hline
\end{tabular}




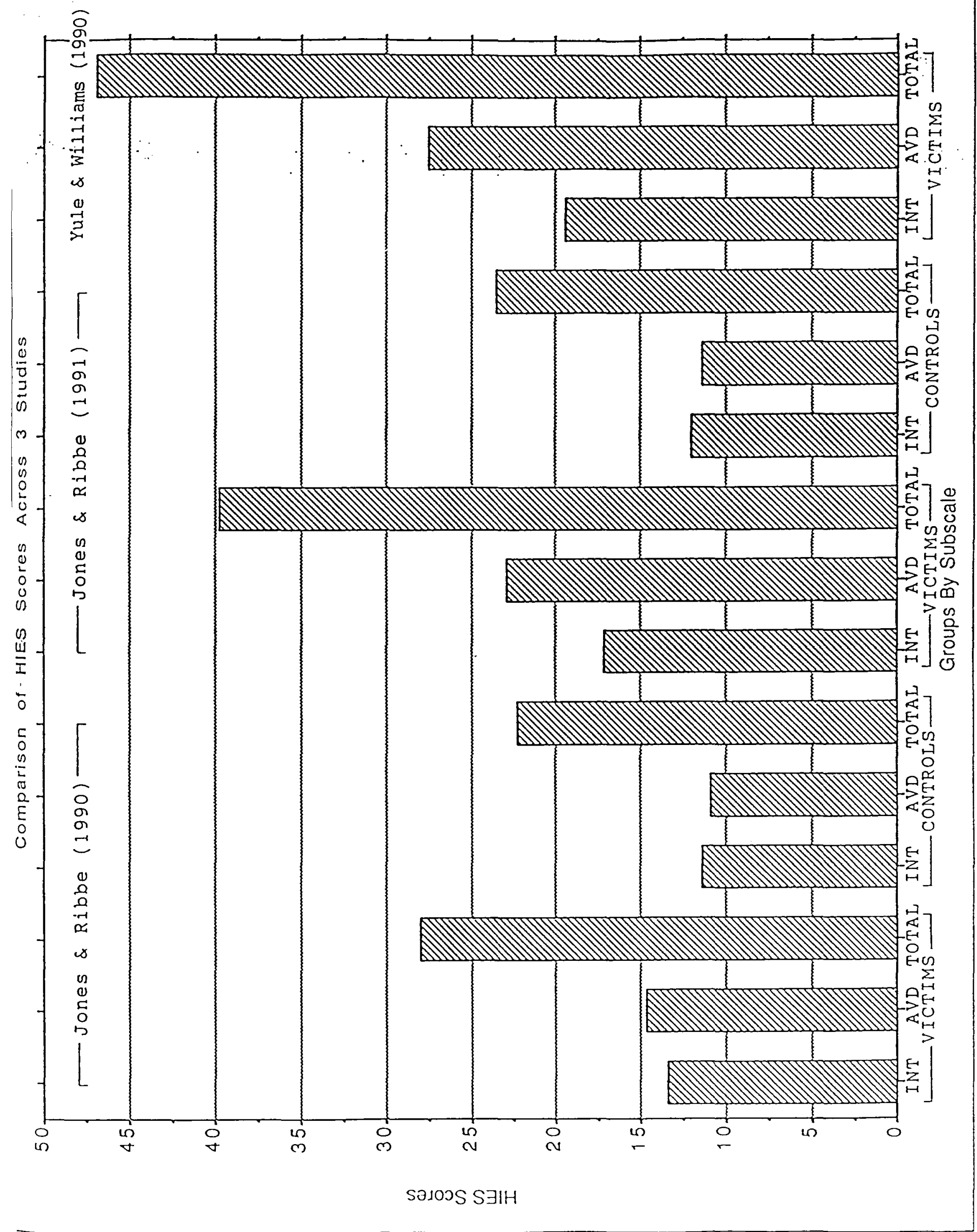

